See Article page 498.

\section{Commentary: The hinge point doubles down-What's next for descending thoracic and thoracoabdominal aortic repair}

\author{
Joseph S. Coselli, MD
}

Despite decades of study, there remains much to be learned about the natural history of descending thoracic and thoracoabdominal aortic pathology, both aneurysmal and dissection. In 1986, with limited information available on the natural history of distal aortic aneurysms, Crawford and DeNatale reported the long-term results of a small number of patients $(\mathrm{n}=94)$ with thoracoabdominal aortic aneurysm who qualified for surgery after evaluation; ultimately, these patients were not operated on and were followed without surgical intervention over a 25 -year period. Crawford and DeNatale observed that the natural history of this disease was dismal—only $24 \%$ of patients were alive at 2 years after evaluation, with one-half of all deaths due to rupture. ${ }^{1}$ In 1999, Randall Griepp and associates provided additional insight into the natural history of descending thoracic and thoracoabdominal aortic disease, studying 165 patients with degenerative aneurysm or chronic aortic dissection who were initially managed nonoperatively. ${ }^{2}$ Like Crawford and DeNatale, Griepp's group found a substantial rate of rupture $(20 \%)$ during long-term observation, as well as high mortality in patients experiencing rupture, ranging from $75 \%$ in patients with degenerative aneurysm to $90 \%$ in patients with chronic dissection. They found that aneurysms related to chronic dissection were at an elevated risk of rupture at smaller aortic dimensions compared with those who had degenerative aneurysms $(5.4 \quad \mathrm{~cm} \quad$ vs $5.8 \mathrm{~cm})$. In

From the Division of Cardiothoracic Surgery, Michael E. DeBakey Department of Surgery, Baylor College of Medicine, Department of Cardiovascular Surgery, Texas Heart Institute, and CHI St Luke's Health-Baylor St. Luke's Medical Center, Houston, Tex.

Disclosures: Dr Coselli consults for, receives royalties and a departmental educational grant from, and participates in clinical trials for Terumo Aortic; consults and participates in clinical trials for Medtronic and W. L. Gore \& Associates, and serves as a coinvestigator for CytoSorbents. Dr Coselli's work is supported in part by the Cullen Foundation.

Received for publication Nov 1, 2019; revisions received Nov 1, 2019; accepted for publication Nov 3, 2019; available ahead of print Nov 27, 2019.

Address for reprints: Joseph S. Coselli, MD, One Baylor Plaza, BCM 390, Houston, TX 77030 (E-mail: jcoselli@bcm.edu).

J Thorac Cardiovasc Surg 2021;161:512-3

0022-5223/\$36.00

Copyright (c) 2019 by The American Association for Thoracic Surgery

https://doi.org/10.1016/j.jtcvs.2019.11.029

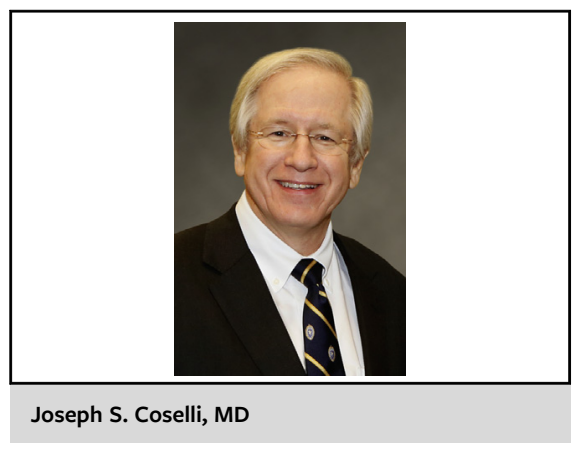

CENTRAL MESSAGE

The descending thoracic and

thoracoabdominal aorta appear

to dilate more quickly than pre-

viously thought; likewise, the risk

of an acute aortic event may

occur at a smaller diameter.

Should the diameter-based

threshold of repair be shifted

lower?

addition, they developed a formula to weigh the risk of aortic rupture versus the risk of surgery to better manage patients.

Over the years, John Elefteriades and others at Yale ${ }^{3,4}$ have provided us with crucial information regarding the natural history of thoracic aortic disease by analyzing the robust database at the Aortic Institute at Yale-New Haven Hospital, which now includes data from nearly 4000 patients with thoracic aortic disease. In this issue of the Journal, Mohammad Zafar and coauthors at Yale ${ }^{5}$ review a subset of patients with serial radiographic studies ( $\mathrm{n}=2384)$ after excluding patients $(\mathrm{n}=1477)$ with congenital aortic malformation, traumatic aortic lesion, intramural hematoma, penetrating atherosclerotic aortic ulcer, iatrogenic aortic dissection, chronic aortic dissection (either Stanford type A or B aortic dissection) at the time of presentation to their center, and syndromic patients (ie, Marfan, Ehlers-Danlos, and Loeys-Dietz syndromes), as well as those patients with a descending thoracic aortic $\leq 3 \mathrm{~cm}$ in diameter. Longitudinal data from the resulting 907 patients were analyzed — a much larger study than prior natural history studies from our colleagues at Yale ${ }^{3,4}$ or the studies by Crawford and colleagues ${ }^{1}$ and Griepp and colleagues. ${ }^{2}$ 
For patients with clear-cut symptoms (such as pain in patients with a contained rupture), there is general agreement that operative intervention should be performed on an urgent or emergent basis in nearly all patients. The authors point out that the current international guidelines recommend preemptive surgical intervention for asymptomatic patients once an aortic diameter of 5.5 to $6.0 \mathrm{~cm}$ is reached. ${ }^{6,7}$ However, it is well known that adverse aortic events-aortic dissection, rupture, and death-may occur in patients whose aortic size has not yet reached those dimensions. The authors report an important finding, that it may be impossible to use a diameter-based threshold of repair to prevent type B aortic dissection; the median diameter before dissection was only $4.1 \mathrm{~cm}$, which is far below current guidelines. Fortunately, patients who experience type B aortic dissection typically survive, and there is little incentive to push for a lower threshold.

In addition, Zafar and coauthors determined the rate of distal aortic growth, finding an average growth rate of $0.19 \mathrm{~cm}$ per year that increased as the aorta grew larger. This rate was nearly double that previously determined by the Yale group. ${ }^{3}$ Likewise, the hinge point-the diameter at which the risk of a catastrophic aortic event is strikingly apparent-changed from that previously identified by this group. In a 1999 report, Coady and colleagues ${ }^{3}$ noted that the risk of a serious distal aortic complication increased dramatically at $7.0 \mathrm{~cm}$ (the hinge point); thus, the target for repair was set at $6.5 \mathrm{~cm}$ to avoid complication. In the study of Zafar and colleagues, the sample size was sufficiently large to allow analysis of the risk of aortic rupture and aortic death separately. Here the hinge points of these catastrophic events have shifted to lower diameters:
$6.0 \mathrm{~cm}$ for aortic death and $6.6 \mathrm{~cm}$ for aortic rupture. As a result, the authors suggest that the targets for aortic repair shift lower, to a range of 5.0 to $5.5 \mathrm{~cm}$, that can then be fine-tuned by patient-specific factors. Although it may be time to double down on the threshold of repair, only experienced aortic centers with outstanding results should manage patients toward elective repair at the lower end of this range $(5.0 \mathrm{~cm})$.

\section{References}

1. Crawford ES, DeNatale RW. Thoracoabdominal aortic aneurysm: observations regarding the natural course of the disease. J Vasc Surg. 1986;3: 578-82.

2. Griepp RB, Ergin MA, Galla JD, Lansman SL, McCullough JN, Nguyen KH, et al Natural history of descending thoracic and thoracoabdominal aneurysms. Ann Thorac Surg. 1999;67:1927-30; discussion 53-8.

3. Coady MA, Rizzo JA, Hammond GL, Kopf GS, Elefteriades JA. Surgical intervention criteria for thoracic aortic aneurysms: a study of growth rates and complications. Ann Thorac Surg. 1999;67:1922-6; discussion 53-8.

4. Coady MA, Rizzo JA, Hammond GL, Mandapati D, Darr U, Kopf GS, et al. What is the appropriate size criterion for resection of thoracic aortic aneurysms? J Thorac Cardiovasc Surg. 1997;113:476-91; discussion 89-91.

5. Zafar MA, Chen JF, Wu J, Li Y, Papanikolaou D, Charilaou P, et al. Natural history of descending thoracic and thoracoabdominal aortic aneurysms. J Thorac Cardiovasc Surg. 2021;161:498-511.e1.

6. Erbel R, Aboyans V, Boileau C, Bossone E, Bartolomeo RD, Eggebrecht H, et al The Task Force for the Diagnosis and Treatment of Aortic Diseases of the European Society of Cardiology (ESC). 2014 ESC guidelines on the diagnosis and treatment of aortic diseases: document covering acute and chronic aortic diseases of the thoracic and abdominal aorta of the adult. Eur Heart J. 2014;35: 2873-926.

7. Hiratzka LF, Bakris GL, Beckman JA, Bersin RM, Carr VF, Casey DE Jr, et al 2010 ACCF/AHA/AATS/ACR/ASA/SCA/SCAI/SIR/STS/SVM guidelines for the diagnosis and management of patients with Thoracic Aortic Disease: a report of the American College of Cardiology Foundation/American Heart Association Task Force on Practice Guidelines, American Association for Thoracic Surgery, American College of Radiology, American Stroke Association, Society of Cardiovascular Anesthesiologists, Society for Cardiovascular Angiography and Interventions, Society of Interventional Radiology, Society of Thoracic Surgeons, and Society for Vascular Medicine. Circulation. 2010;121:e266-369. 